\title{
MENINGKATKAN HASIL BELAJAR DENGAN MODEL PEMBELAJARAN TEAMS GAMES TOURNAMENTS
}

\author{
Yayah Afiah \\ e-mail: alimzuhri@gmail.com \\ Sekolah Menengah Atas Negeri 15 Jakarta
}

\begin{abstract}
Abstrak: Pemahaman siswa di kelas X-7 tentang penulisan paragraf argumentatif masih rendah. Hal tersebut disebabkan kurangnya siswa mendengarkan penjelasan guru, kurangnya siswa memperhatikan ketetapan ejaan, pilihan kata, keefektifan kalimat, keterpaduan paragraf, dan kebulatan wacana. Untuk memecahkan persoalan ini, peneliti melakukan penelitian tindakan dengan tujuan meningkatkan kemampuan siswa tentang penulisan paragraf argumentatif. Penelitian dilakukan di kelas X-7 SMA Negeri 15 Jakarta pada bulan Januari sampai bulan Februari 2012 dengan menggunakan model pembelajaran Teams Games Tournaments (TGT). Setelah melalui dua siklus, ternyata nilai rata-rata siswa mencapai 72 dengan prosentase ketuntasan telah mencapai $75 \%$. Dengan demikian dapat disimpulkan bahwa penggunaan metode pembelajaran TGT dapat meningkatkan hasil belajar Bahasa Indonesia siswa pada pokok bahasan paragraf argumentasi.
\end{abstract}

Kata kunci: paragraf argumentatif, model pembelajaran, Teams Games Tournaments, hasil belajar.

\section{IMPROVING LEARNING ACHIEVEMENT APPLYING COOPERATIVE LEARNING MODEL WITH TEAMS GAMES TOURNAMENTS}

\begin{abstract}
Abstrak: The Grade X-7 students' understanding of writing argumentative paragraph is still low as the students do not listen to the teacher's explaination attentively, do not care the use of correct spelling, diction, effective sentence, paragraph coherence, and integerated passage. To overcome these problems, the researcher performed classroom action research aiming at imroving the students' competence in writing argumentative paragraph. The research was conducted in Grade X-7 of State High School, No. 7, in Jakarta as from January through February $2012 \mathrm{em}$ ploying Teams Games Tournaments (TGT) Model. After the second cycle of the research, the students' learning achievement indicated the average of 72 with the learning mastery of $75 \%$ showing the significant improvement. It was concluded that TGT Model can be used to improve the students' learning achievement in argumentative paragraph writing. Besides, the research recommended a set of steps how to use the model.
\end{abstract}

Keywords: argumentative paragraph, instructional model, Teams Games Tournament, learning achievement.

\section{PENDAHULUAN}

Bahasa merupakan alat komunikasi yang paling penting bagi kehidupan manusia. Bahasa dapat dijadikan media penyampaian informasi dari satu individu ke individu lain secara tidak langsung. Mengggunakan bahasa yang baik dalam diri seseorang akan membantu keharmonisan orang tersebut dalam berkomunikasi dengan baik di masyarakat. Fungsi utama bahasa adalah sebagai alat komunikasi. Oleh karena itu, pembelajaran bahasa dan sastra Indonesia diarahkan agar siswa terampil berkomunikasi, baik lisan maupun tulisan. Pembelajaran bahasa selain untuk meningkatkan keterampilan berbahasa, juga untuk meningkatkan kemampuan berpikir, mengungkapkan gagasan, perasaan, pendapat, persetujuan, keinginan, penyampaian informasi tentang suatu peristiwa dan kemampuan memperluas wawasan.

Kemampuan berbahasa dalam pelaksanaannya dibagi dua yaitu kemampuan produktif atau menghasilkan dan kemampuan resentif atau menerima. Kemampuan produktif terdiri dari kemampuan berbahasa dan menulis, sedangkan kemampuan resitif yaitu kemampuan menyimak dan membaca.Keterampilan menulis yang merupakan kegiatan produktif mempunyai arti menuntut seseorang untuk menghasilkan sebuah karya miliknya agar dapat dimanfaatkan oleh orang lain. Tak hanya itu, keterampilan menulis dirasakan paling sukar, karena seseorang dituntut untuk mengkoordinasikan ketiga aspek keterampilan lainnya, yaitu menyimak, berbicara, dan membaca secara maksimal.

Menulis merupakan suatu keterampilan berbahasa yang dipergunakan untuk berkomunikasi secara 
tidak langsung. Menulis adalah suatu kegiatan yang aktif dan produktif serta memerlukan cara berpikir yang teratur yang diungkapkan dalam bahasa tulis. Menulis dipengaruhi oleh keterampilan produktif lainnya, seperti aspek berbicara, aspek membaca dan menyimak serta pemahaman kosa kata, diksi, penggunaan ejaan dan tanda baca.

Dari keempat segi keterampilan berbahasa yaitu menyimak, membaca, berbicara, dan menulis tersebut, yang jarang diterapkan di kelas adalah kegiatan menulis karena kegiatan ini lebih sering ditugaskan sebagai pekerjaan rumah. Menulis bukanlah sesuatu yang asing buat kita, sebagai contoh produk dari bahasa tulis yang ada dalam kehidupan sehari-hari adalah laporan, artikel, majalah, buku fiksi, buku nonfiksi, dan lain-lain. Tulisan tersebut menyajikan secara runtut dan menarik tentang ide, gagasan, serta perasaan penulisnya.

Pada Kurikulum Tingkat Satuan Pendidikan (KTSP) standar kompetensi menulis kelas X antara lain disebutkan mengungkapkan informasi dalam berbagai bentuk paragraf (naratif, argumentatif, ekspositif). Artinya bahwa siswa kelas X SMA, dituntut memiliki dasar keterampilan menulis paragraf argumentatif. Dengan menulis siswa dapat mengungkapkan gagasan, pendapat, pemikiran, dan perasaan yang dimiliki. Kemampuan menulis juga merupakan salah satu kemampuan yang harus banyak dilatihkan kepada siswa. Semakin banyak siswa menulis akan semakin baik pula kemampuannya dalam menghasilkan sebuah tulisan. Menulis gagasan untuk mendukung suatu pendapat dalam bentuk paragraf argumentatif.

Paragraf argumentatif adalah paragraf yang isinya bertujuan untuk mempengaruhi pikiran, pendapat atau sikap pembaca sehingga pembaca mempercayai dan mengikuti apa yang disampaikan penulis. Tujuannya untuk meyakinkan pembaca sehingga mereka membenarkan pendapat, sikap, dan keyakinan penulis. Ciri-ciri paragraf argumentatif menjelaskan pendapat agar pembaca menjadi yakin, dengan menggunakan fakta untuk pembuktian berupa gambar dan lain-lainnya. Paragraf ini menggali sumber ide dari pengamatan, pengalaman, dan pemikiran, serta penutup berisi kesimpulan.

Pada saat pembelajaran menulis karangan paragraf argumentatif di kelas $X$, ada kendala yang dihadapi oleh siswa. Kendala tersebutdisebabkan oleh guru, siswa, media pembelajaran, model pembelajaran, atau dari lingkungan sekolah. Berdasarkan hasil pengamatan peneliti, dalam pembelajaran menulis karangan berpola paragraf argumentatif terlihat bahwa sebagian besar keterampilan menulis siswa masih sa- ngat terbatas. ada beberapa siswa menyatakan bahwa mereka merasa kesulitan untuk dapat membedakan jenis-jenis paragraf dan menyusun kerangka paragraf argumentatif.

Umumnya model pembelajaran yang diterapkan di sekolah adalah metode ceramah atau eksploitasi. Model pembelajaran ini juga diterapkan pada mata pelajaran Bahasa Indonesia dan membuat siswa merasa jenuh karena keaktifan siswa tidak begitu diperhatikan. Siswa menjadi bosan dan kurang motivasi dalam belajar bahasa Indonesia karena kondisi dan situasi belajar yang monoton. Untuk mengatasi keadaan tersebut, diduga dengan menerapkan model pembelajaran Teams Games Tournaments (TGT) dapat meningkatkan hasil belajar siswa dalam belajar Bahasa Indonesia pada pokok bahasan penulisan paragraf argumentative. Model pembelajaran Teams Games Tournaments (TGT) adalah model pembelajaran yang membagi siswa dalam kelompok kecil dengan anggota 4-5 orang yang berkemampuan heterogen. Kelompok kecil ini saling bekerja sama, berdiskusi, dan tolong-menolong untuk memecahkan masalah. Setiap individu harus memberikan kontribusinya untuk pencapaian skor kelompok. Sedangkan antar kelompok, mereka harus saling berkompetisi. Kelompok yang mendapat skor tertinggi akan mendapatkan penghargaan atau team reward.

Berdasarkan alasan yang telah diutarakan, maka penelitian ini menerapkan model pembelajaran Teams Games Tournaments (TGT) pada pokok bahasan penulisan paragraf argumentasi. Diharapkan siswa akan lebih termotivasi untuk belajar menulis, karena siswa secara langsung ikut terlibat pada proses pembelajaran yang sedang dilaksanakan. Dengan menggunakan metode pembelajaran Teams Games Tournaments (TGT) hasil belajar siswa untuk pelajaran bahasa Indonesia meningkat khususnya pada penulisan paragraf argumentasi.

\section{METODE PENELITIAN}

\section{Jenis Penelitian}

Penelitian ini termasuk ke dalam Classroom Action Research atau Penelitian Tindakan Kelas (PTK). Penelitian ini menggunakan metode penelitian tindakan kelas dengan dua siklus.

\section{Tempat dan Waktu Penelitian}

Penelitian dilaksanakan di SMA Negeri 15 Jakarta di kelas X pada tahun pelajaran 2011/2012, selama 2 bulan sejak bulan Januari sampai dengan Februari tahun 2012.

\section{Prosedur Penelitian}

a. Sumber Data 
Data yang diambil bersumber pada kegiatan pembelajaran siswa kelas X-7 di SMAN 15 Jakarta.

b. Teknik Pengumpulan Data

Teknik pengumpulan data dilakukan melalui kuesioner, pretest, dan post test.

\section{HASIL DAN PEMBAHASAN}

Adapun hasil penilaian ini diperoleh dari kegiatan siklus I dan siklus II. Data penelitian ini berupa hasil penelitian ulangan sebagai hasil tes dan hasil kuesioner sebagai hasil nontes. Siklus I terdiri dari 4 tahap yaitu: (1) perencanaan (planning), meliputi membuat rencana pelaksanaan pembelajaran (RPP), menyiapkan lembar instrumen penelitian yang terdiri dari lembar observasi atau pengamatan kegiatan pembelajaran siswa, lembar daftar hadir siswa, bahan ajar, dan tes individu; (2) pelaksanaan (action), diawali dengan pembagian kelompok siswa, dengan menggunakan model pembelajaran Teams Games Tournaments (TGT). Siswa menulis paragraf argumentatif, guru mengamati dan membantu kelompok yang mengalami kesulitan; (3) monitoring, dan (4) evaluasi serta refleksi.

Tabel 1.

Hasil Angket Tentang Persepsi Siswa Terhadap Mata Pelajaran Bahasa Indonesia Tentang Paragraf Argumentasi Sebelum Tindakan Kelas Dilakukan

\begin{tabular}{|c|c|c|c|c|c|}
\hline \multirow[t]{2}{*}{ No } & \multirow[t]{2}{*}{ Pernyataan } & \multicolumn{2}{|c|}{$\begin{array}{l}\text { Jawaban } \\
\text { Siswa }\end{array}$} & \multicolumn{2}{|c|}{$\%$} \\
\hline & & Ya & Tdk & $\mathrm{Ya}$ & Tdk \\
\hline 1. & $\begin{array}{l}\text { Apakah Anda menyukai pelaja- } \\
\text { ran Bahasa Indone-sia? }\end{array}$ & 36 & 4 & 90 & 10 \\
\hline 2. & $\begin{array}{l}\text { Apakah Anda pernah membaca } \\
\text { sebuah karang-an? }\end{array}$ & 36 & 4 & 90 & $10 \%$ \\
\hline 3. & $\begin{array}{l}\text { Apakah Anda pernah membaca } \\
\text { sebuah karang-an argumentasi? }\end{array}$ & 30 & 10 & 75 & $25 \%$ \\
\hline 4. & $\begin{array}{l}\text { Apakah Anda pernah menulis } \\
\text { sebuah paragraf? }\end{array}$ & 30 & 10 & 75 & $25 \%$ \\
\hline 5. & $\begin{array}{l}\text { Apakah Anda pernah menulis } \\
\text { karangan argumentasi? }\end{array}$ & 25 & 15 & 62,5 & 37,5 \\
\hline 6 & $\begin{array}{l}\text { Apakah Anda merasa kesulitan } \\
\text { dalam menulis karangan argu- } \\
\text { mentasi? }\end{array}$ & 27 & 13 & 65 & 35 \\
\hline 6 & $\begin{array}{l}\text { Apakah Anda merasa kesulitan } \\
\text { dalam menulis karangan argu- } \\
\text { mentasi? }\end{array}$ & 27 & 13 & 65 & 35 \\
\hline 7 & $\begin{array}{l}\text { Pernahkan sebelum menulis } \\
\text { karangan argumentasi Anda } \\
\text { membuat kerangka karangan } \\
\text { terlebih dahulu? }\end{array}$ & 23 & 17 & 57.5 & 42.5 \\
\hline 8. & $\begin{array}{l}\text { Pernahkah Anda belajar Bahasa } \\
\text { Indonesia secara berkelompok? }\end{array}$ & 30 & 10 & 75 & 25 \\
\hline 9. & $\begin{array}{l}\text { Apakah Anda senang belajar } \\
\text { Bahasa Indonesia secara berke- } \\
\text { lompok? }\end{array}$ & 30 & 10 & 75 & 25 \\
\hline
\end{tabular}

Hasil evaluasi awal pada proses belajar mengajar, penguasaan siswa terhadap menulis paragraf argumentatif tanpa menggunakan model pembelajaran Teams Games Tournaments (TGT) dapat dilihat pada tabel 1.

Dari data di atas dapat dimengerti bahwa siswa jarang belajar secara berkelompok, dan jarang diberi latihan menulis. Hasil Evaluasi siklus I, setelah siswa mengikuti proses kegiatan belajar bahasa Indonesia dengan menggunakan model pembelajaran Teams Games Tournaments (TGT) dapat dilihat pada Gambar 1.

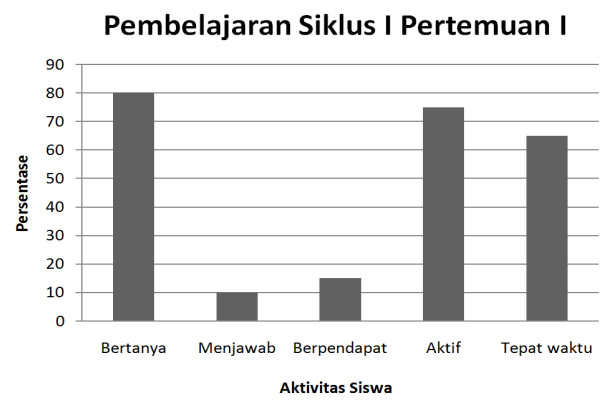

Gambar 1. Diagram Batang Hasil Pengamatan Aktivitas Siswa Pada Pembelajaran Siklus I Pertemuan 1

Data di atas menunjukkan aktivitas siswa pada pembelajaran bahasa Indonesia, yang mengajukan lima pertanyaan ada 32 siswa atau $80 \%$, menjawab pertanyaan sebanyak 4 siswa atau $10 \%$, dan memberikan pendapat pada saat kegiatan presentasi hanya 6 siswa atau $15 \%$, dan aktif dalam diskusi, baik kelompok maupun klasikal ada 30 siswa atau 75\%, dan ketepatan siswa dalam mengumpulkan tugas pekerjaan rumah ada 26 siswa atau $65 \%$.

Selanjutnya pada siklus I pertemuan 2 menggambarkan hasil belajar tiap kelompok, di bawah ini disajikan diagram batang yang menunjukkan skor tiap kelompok.

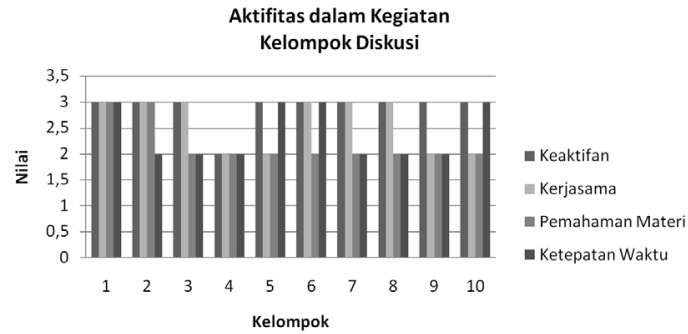

Gambar 2. Diagram Batang Tentang Nilai Aktifitas

Dalam Kegiatan Kelompok Diskusi

Refleksi , beberapa faktor yang mempengaruhi belum berhasilnya sebagian siswa, terlihat masih banyak siswa yang belum mendapatkan nilai lebih besar atau sama dengan KKM dikarenakan sebagian siswa belum terlatih untuk belajar menulis paragraf argumentatif dan sebagian siswa masih belum terbiasa belajar kelompok. 
Pada siklus I pertemuan 3 diperoleh nilai ratarata individu dalam menulis paragraf argumentatif pada tabel 2.

Tabel 2. Nilai Rata-rata dan Ketuntasan Belajar pada Siklus I

\begin{tabular}{|c|c|c|c|c|}
\hline No & Nilai Rata-Rata & Daya Serap & KKM & Ketuntasan (\%) \\
\hline 1 & 68,75 & $68,75 \%$ & 70 & 72,5 \\
\hline
\end{tabular}

Hasil Evaluasi siklus I: nilai rata-rata Bahasa Indonesia pada siklus I ini adalah 68,75 dengan ketuntasan belajarnya $72,5 \%$. Hal ini dapat terjadi karena masih terdapat beberapa siswa yang belum tuntas dan harus dilakukan remedial untuk kompetensi dasar yang belum tuntas. Dengan demikian maka siklus II dipandang perlu untuk dilakukan.

Siklus II meliputi perencanaan yang memfokuskan pada pemberian motivasi belajar baik secara kelompok maupun individu. Siklus II adalah tindak lanjut dari siklus I, pelaksanaannya lebih terencana, terarah sehingga harapannya motivasi dan hasil belajar siswa lebih meningkat disbanding siklus I.

Monitoring dan Evaluasi, hasil siklus II merupakan perbaikan dari siklus I. Berikut hasil siklus II tentang aktivitas siswa pada pembelajaran menulis paragraf argumentatif.

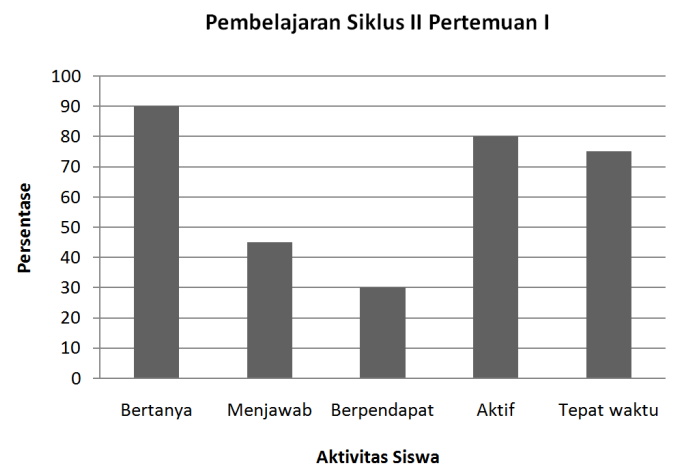

Gambar 3. Diagram Batang Hasil Pengamatan Aktivitas Siswa Pada Siklus II Pertemuan 1

Data di atas menunjukkan terdapat 36 siswa atau $90 \%$ mengajukan pertanyaan, menjawab pertanyaan ada 18 siswa atau $45 \%, 12$ siswa atau $30 \%$ yang memberikan pendapat pada saat kegiatan presentasi, aktif dalam diskusi baik kelompok maupun klasikal 32 siswa atau $80 \%$, dan ketepatan mengumpulkan tugas pekerjaan rumah ada 30 siswa atau $75 \%$.

Untuk menggambarkan hasil belajar tiap kelompok, di bawah ini disajikan diagram batang yang akan menunjukkan kelompok mana yang tertinggi skornya dan kelompok mana yang terendah skornya.

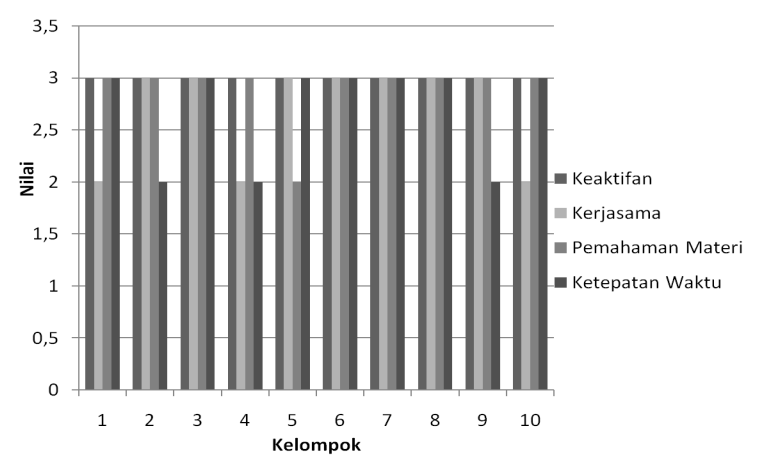

Gambar 4. Diagram Batang Tentang Nilai Kelompok Dalam Pembuatan Topik dan Kerangka Paragraf

Terlihat bahwa ada peningkatan nilai yang diraih oleh siswa pada evaluasi siklus II ini dibandingkan dengan nilai pada siklus I, dimana jumlah siswa yang meraih nilai di atas KKM 70 mencapai 30 siswa, dengan perolehan nilai tertinggi adalah 90. Untuk melihat perkembangan secara lebih konkretnya, data tersebut diolah dan disajikan dalam bentuk nilai ratarata seperti yang tertera pada tabel 3 .

Tabel 3. Nilai Rata-rata dan Ketuntasan Belajar pada Siklus II

\begin{tabular}{|c|c|c|c|c|}
\hline No & Nilai Rata-Rata & Daya Serap & KKM & Ketuntasan (\%) \\
\hline 1 & 72 & $72 \%$ & 70 & 75 \\
\hline
\end{tabular}

Refleksi, pencapaian hasil belajar pada siklus II dapat direfleksikan sebagai berikut: (a) motivasi belajar siswa sudah baik dikarenakan siswa sudah terbiasa belajar secara kelompok, (b) kreatifitas guru dalam menyajikan materi juga mendukung motivasi belajar siswa dikelas, hal ini terlihat dari naiknya nilai rata-rata siswa.

Dari seluruh analisis di atas dapat disimpulkan bahwa aktifitas siswa pun meningkat, seperti yang tertera pada tabel 4.

Tabel 4. Peningkatan Nilai Aktifitas Siswa Pada Siklus I dan II

\begin{tabular}{|c|l|c|c|c|c|}
\hline \multirow{2}{*}{ No } & \multicolumn{2}{|c|}{$\begin{array}{c}\text { Komponen Yang } \\
\text { Diamati }\end{array}$} & \multicolumn{2}{c|}{ Siklus I } & \multicolumn{2}{c|}{ Siklus II } \\
\cline { 4 - 6 } & \multicolumn{1}{|c|}{ Jml } & $\%$ & Jml & $\%$ \\
\hline 1 & Bertanya kepada guru & & & & \\
\hline 2 & Menjawab pertanyaan guru & & & & \\
\hline 3 & Memberikan pendapat & & & & \\
\hline 4 & Aktif dalam diskusi & & & & \\
\hline 5 & Ketepatan mengumpulkan & & & & \\
\hline
\end{tabular}


Selain aktifitas siswa, hasil belajar yang diperoleh siswa selama siklus I dan siklus II mengalami kenaikkan yang cukup signifikan.

Tabel 5. Hasil Belajar Siswa

\begin{tabular}{|c|l|c|c|}
\hline \multirow{2}{*}{ No } & \multirow{2}{*}{ Kriteria } & \multicolumn{2}{c|}{$\%$} \\
\cline { 3 - 4 } & & Siklus I & Siklus II \\
\hline 1 & Rata-rata Nilai & 68,75 & 72 \\
\hline 2 & Daya Serap & 68,75 & 72 \\
\hline 3 & KKM & 70 & 70 \\
\hline 4 & Ketuntasan & 72 & 75 \\
\hline
\end{tabular}

Hal ini berarti model pembelajaran Teams Games Tournaments (TGT) dapat meningkatkan hasil belajar siswa pada pelajaran bahasa Indonesia.

\section{PENUTUP}

\section{Kesimpulan}

Dari hasil pembahasan yang sudah diuraikan sebelumnya, maka dapat ditarik kesimpulan bahwa penggunaan metode kooperatif Team Games Tournament (TGT) dengan menggunakan Lembar Kerja Siswa (LKS) dapat meningkatkan hasil belajar siswa pada mata pelajaran Bahasa Indonesia di SMA Negeri 15 Jakarta. Pada siklus I rata-rata hasil belajar Bahasa Indonesia adalah 68,75 , sedangkan pada siklus II ratarata hasil belajar Bahasa Indonesia adalah 72 berarti mengalami kenaikan sekitar 3,25 poin, dengan hasil akhir pencapaian persentase ketuntasan $75 \%$ sesuai yang diharapakan pada tahap perencanaan.

Selain hasil belajar, aspek keaktifan siswa dalam kegiatan pembelajaran juga mengalami prosentase kenaikan angka dari siklus kesatu dibandingkan siklus kedua, seperti sikap antusias dalam belajar dan keberanian dalam bertanya. Sehingga metode Kooperatif Teams Games Tournaments (TGT) dapat meningkatkan hasil belajar siswa pada mata pelajaran bahasa Indonesia.

\section{Saran}

Pembelajaran dengan menggunakan metode Kooperatif Team Games Tournament (TGT) dengan alat-alat peraga yang dipadukan dapat diterapkan pada mata pelajaran lain dan pokok bahasan apapun sehingga sangat baik jika dikombinasikan dengan metode lainnya agar pembelajaran lebih mudah dipahami siswa dan menyenangkan bagi siswa.

\section{DAFTAR PUSTAKA}

Achyar., dkk. (1996). Cooperative learning strategies in the teaching of general science at lower secondary school. Malaysia : Seameo Recsam

Akhadiah, S., Arsjad, M \& Ridwan, S. (1988). Pembinaan kemampuan menulis bahasa Indonesia. Jakarta: Erlangga.

Alwasilah, A.C \& Alwasilah, S.S. (2005). Pokoknya menulis. Bandung: PT Kiblat Buku Utama.

Arikunto, S., dkk. (1990). Penelitian tindakan kelas. Jakarta : Bumi Aksara.

Departemen Pendidikan dan Kebudayaan. (1978). Buku pelajaran bahasa Indonesia, sekolah menengah atas. Jilid 3. Jakarta : Balai Pustaka.

Djamarah, S.B. (2000). Guru dan anak didik dalam interaksi edukatif. Jakarta: Rineka Cipta.

Elbow, P. (1973). Writing without teacher. New York: Oxford University Press.

http:/ / uki-edukita.blogspot.com/2010/03/ptk-bk. html diunduh pada tanggal 29 Maret 2010.

Isjoni, M.A. \& Ismail. (2008). Model-model pembelajaran mutakhir perpaduan Indonesia Malaysia. Yogyakarta : Pustaka Pelajar.

Keraf, G. (1982). Argumentasi dan narasi. Jakarta : Gramedia Pustaka Utama.

Kusnandar. (2007). Guru profesional. Jakarta : Rajawali Pers Raja Pafindo.

Lie, A. (2002). Cooperative learning. Jakarta : Gramedia. Parera, J.D. (1984). Belajar mengemukakan pendapat. Jakarta : Erlangga.

Semi, M.A. (1990). Menulis efektif. Padang : Angkasa Raya.

Setyadin, B \& Wiyono, B. (2010). Implementasi PTK bagi guru LPMP. Malang : Universitas Negeri Malang.

Slavin, R.E. (2008). Cooperative learning: Teori, riset, dan praktik. Bandung: Nusa Media.

Suyanto M.S., J. Ch. (1988). Keterampilan berbahasa ,membaca-menulis-berbicara untuk mata kuliah dasar umum bahasa Indonesia. Jakarta : Departemen Pendidikan dan Kebudayaan.

Trianto. (2007). Model-model pembelajaran inovatifberorientasi konstruktivistik. Jakarta: Prestasi Pustaka.

Wibowo, W. (2006). Berani menulis artikel. Jakarta : Gramedia Pustaka Utama.

Wiriaatmadja, R. (2007). Metode penelitian tindakan kelas untuk meningkatkan kinerja guru dan dosen. Bandung: Remaja Rosda Karya. 